\title{
Article \\ Cumulative Risks of Excipients in Pediatric Phytomucolytic Syrups: The Implications for Pharmacy Practice
}

\author{
Kateryna O. Zupanets ${ }^{1, *(\mathbb{D})}$, Sergii K. Shebeko ${ }^{1} \mathbb{D}$, Kseniia L. Ratushna ${ }^{1} \mathbb{D}$ and Oleksandr V. Katilov ${ }^{2} \mathbb{D}$ \\ 1 Department of Clinical Pharmacology and Clinical Pharmacy, \\ National University of Pharmacy, 61057 Kharkiv, Ukraine; shebeko.sk@gmail.com (S.K.S.); \\ pharmaxena@gmail.com (K.L.R.) \\ 2 Department of Propedeutics of Pediatric Diseases, National Pirogov Memorial Medical University, \\ 21018 Vinnytsya, Ukraine; alexkatilov@gmail.com \\ * Correspondence: katyazupanets@gmail.com; Tel.: +38-067-917-4273
}

check for updates

Citation: Zupanets, K.O.; Shebeko, S.K.; Ratushna, K.L.; Katilov, O.V. Cumulative Risks of Excipients in Pediatric Phytomucolytic Syrups: The Implications for Pharmacy Practice. Sci. Pharm. 2021, 89, 32. https:// doi.org/10.3390/scipharm89030032

Academic Editor: Helen D. Skaltsa

Received: 13 May 2021

Accepted: 1 July 2021

Published: 5 July 2021

Publisher's Note: MDPI stays neutral with regard to jurisdictional claims in published maps and institutional affiliations.

Copyright: (c) 2021 by the authors. Licensee MDPI, Basel, Switzerland. This article is an open access article distributed under the terms and conditions of the Creative Commons Attribution (CC BY) license (https:// creativecommons.org/licenses/by/ $4.0 /)$.

\begin{abstract}
Expectorant phytomucolytic syrups are widely used pediatric OTC-medicines. Physicians, pediatricians, and pharmacists are traditionally concerned with the efficacy of the active ingredients in cough syrups, and rarely consider the safety aspects of excipients that however are not absolutely "inactive" and are proved to initiate some negative reactions and interactions with other drugs. This paper presents a review, categorization, and comparative analysis of the safety profile of excipients contained in the 22 best-selling OTC pediatric phytomucolytic syrups available in pharmaceutical markets in Ukraine and Germany and proposes an approach to the consideration of the excipients' safety risks for a pharmacist in the process of pharmaceutical care. The study has revealed that only one of the twenty-two analyzed syrups does not contain any potentially harmful excipients. The results of this analysis were used for developing a specific decision tool for pharmacists that can be used for minimizing excipient-initiated reactions when delivering OTC phytomucolytic syrups for children.
\end{abstract}

Keywords: phytomucolytic syrup; excipients; pharmaceutical care; pediatric medicines

\section{Introduction}

The cough syrup market size was estimated globally at USD 5232.73 million in 2019 and is expected to reach USD 6108.25 million by 2027 [1]. In Ukraine, syrups are one of the most sold drug formulations with more than 27 million EURO sales in 2019 [2]. Because syrups predominantly are a pediatric medical form, the largest portion of these syrups is used by children [3]. A large proportion of pediatric syrups are OTC cough medicines that are highly popular among parents and are prescribed or bought in a pharmacy to relieve cough symptoms in children [4-6].

The NY Times wrote that around $60 \%$ of parents give cough syrups to their children because they help to reduce the discomfort of cold and flu [6]. The common reasons for the wide use of cough syrups are that parents "have to do something, ... that will relieve their children's distress" [6]. In addition, cough syrups have a long history of use and they "figure in many parents' memories of their own sick days ... when they all took these medications themselves" [6]. Thus, it is obvious that pediatric cough syrups are traditionally perceived as a key cold medication.

Technically, syrup is a solution that uses sucrose for the production of viscous preparation [3]. Some syrups may substitute sucrose-based syrup with a solution of polyols, such as sorbitol, or a mixture of polyols, such as sorbitol and glycerin [7]. Overall, the key functional components of a cough syrup include active ingredients and excipients: thickeners, flavors, colors, antimicrobials, and buffers [8]. Most of these excipients are additives used in the food and beverage industry [9]. 
In general, pharmaceutical excipients are pharmacologically inactive components of a drug playing a supporting role in the production of a designed dosage form as well as in its delivery $[10,11]$. However, in syrups, these excipients are crucial, as they can significantly contribute to both their efficacy and safety, some of them can even play the role of the active ingredient of the cough medicine $[12,13]$. Moreover, according to biopharmaceutic principles, the optimal and rational composition of both active ingredients and excipients is essential to provide the efficacy of a medicine [14,15].

The safety of excipients included in pediatric medicines will continue to be a concern for many years and has been discussed by a range of authors. The comprehensive review of Eccles presents the analysis of over 100 excipients in OTC cough medicines including pediatric ones [8]. The use of excipients in the pediatric population is critically reviewed by Rouaz et al. [16], the issues of using coloring agents are reviewed by Pérez-lbarbia et al. [9], and the potential side effects of sweeteners are thoroughly discussed in works of Eccles, Humaid, Christensen, Ruiz-Ojeda et al., Saraiva et al. [7-9,17-25]. Occasionally these concerns were confirmed by reports about bans of authorized pediatric cough syrups due to risky additives found [26].

While there is a growing warning about using pediatric cough medicines with synthetic agents (Acetylcysteine, Carbocysteine, Abroxol, Dextromethorphan, Guaifenesin) especially in young children, the herbal expectorants are still highly used by parents and present a range of advantages $[4,5,27,28]$. According to the literature analyzed, these include prolonged and complex action, ease of symptoms, and improvement of quality of life in both children and parents that take care of a child in distress [4].

The phytomucolytics in syrup formulation perfectly match the expectations of parents concerning cold and cough therapy for their children and are perceived as safe and nontoxic medicines. Thus, little attention is given to the risks of these medications as well as to the fact that some negative effects could be initiated by excipients that are essential components of the syrup.

Physicians, pediatricians, and pharmacists are traditionally concerned with the efficacy of active ingredients in cough syrup and rarely consider the safety aspects of excipients that, however, are not completely "inactive" and are proved to initiate some negative reactions and interactions with other drugs [8]. The latter becomes highly significant, as in practice respiratory infections in children are treated with the usage of several drugs in complex therapy. Considering that cough syrups are highly appreciated by patients as cold medicines, it is possible to assume that a child that has up to 6-8 cases of cold every year regularly consumes large volumes of syrups, becoming exposed to a high risk of adverse reactions and overdose by either active substances or excipients. Hence, it is apparent that the practical aspects of assuring the safety of therapy with pediatric cough syrups remain extremely important and should be carefully considered by medical specialists, especially for young children and those having additional risk factors (allergic disorders, chronic diseases like diabetes, renal and liver dysfunction) [5].

The use of any excipient, as well as the active ingredient of the medicine, must be driven by a risk-based assessment that takes into account factors such as the pediatric age group, frequency of dosing, and duration of treatment $[3,29,30]$. The EMA guideline warns pharmaceutical manufacturers as well as researchers about the necessity to give special safety considerations on any excipient in pediatric preparations [29,31]. It is important to note that no excipient is inert and that they can alter the treatment outcomes when above a certain concentration. One of the risks that must be carefully avoided is allergy and sensitization, as these conditions are more easily arise in early childhood than in adults. Thus, the EMA emphasizes the importance of avoiding excipients with a known potential to cause sensitization or allergies to avoid this negative effect and to broaden possibilities of allergic children therapy [29,32].

According to EU-GMP requirements, manufactures must assure the quality of the excipients used in finished medicine, which should be accompanied by a formalized assessment of excipient risks [33,34]. All these requirements nevertheless do not cover the 
entire scope of risks associated with the real-world practice of pediatric cough medicines use. As phytomucolytic syrups belong to OTC-drugs indicated for reducing one of the most prevalent cold symptoms-cough - there is a high risk of unreasonable and uncontrolled use of phytomucolytic syrups in children by their parents. Moreover, the review of excipients side effects allows the assumption that some of them should be used with caution in particular categories of pediatric patients, e.g., those having diabetes mellitus, gastrointestinal, allergic diseases, CNS and behavioral disorders.

For example, even though the risk assessment profile of excipients relevant for one dosage unit/unit of pharmaceutical product (a bottle of syrup) is satisfied, consistent overdosing or long-term use of cough syrups might augment the potential safety risks of excipients and make them clinically significant-especially for children in risk categories. In the case of self-treatment, consumers often ignore warnings given in package leaflet information which might also be unclear to them. Moreover, excipients labeling requirements vary in different countries, and therefore the safety risks of some potentially harmful excipients remain to be unaddressed in clinical practice.

Thus, the paper highlights that despite the importance of quality assurance measures applied by a manufacturer and the relevant excipients labeling regulations, a range of risks posed by excipients is not eliminated in some phytomucolytic herbal syrups that could be a result of insufficient risk identification, e.g., lack of data on clinical use specifics, lack of standardized and controlled production of herbal products, and gaps in herbal pharmaceutical products regulation. It is worth mentioning that these issues are eliminated in phytoneering products with sound scientific technological design and preclinical and clinical research backgrounds, as will be demonstrated later in this paper. However, some pediatric phytomucolityc syrups remain to be a source of safety risks caused by excipients, which is a hidden threat to children's health. Thus, these risks should be addressed at the "post-production" stage by specialists guiding the therapy process. In this paper, the emphasis is placed on the pharmacist as the one most likely to be the first healthcare professional contacted by parents in the case of cough symptoms in their children.

A pharmacist, as a healthcare specialist, commonly provides advice on OTC-medicines for treating cold and might contribute to evaluating and minimizing the risks associated with pharmaceutical excipients for children. To assure the safety of the treatment, a pharmacist should go beyond the effects of their active ingredients and consider the specific features of the drug excipients in parallel, i.e., toxicity (according to the recent relevant evidence), tolerability (risk of allergies/sensitization, cariogenicity, gastrointestinal osmotic effects and metabolic fate, caloric contribution), the patient's age, the patient's susceptibility (diabetic patients, patients with allergies, etc.), and possible cumulative effect with excipients in concomitant medications [23].

To empower a pharmacist with the ability to consider the effects of excipients on the therapy outcome, specific algorithms are required that describe the logic of drug excipients evaluation and further actions in a particular case. These algorithms should be introduced into the process of pharmaceutical care to significantly advance pharmacist's decisionmaking, assuring a better and more precise choice of OTC drugs for an individual patient.

Additionally, the issue arises when a pharmacist receives a physician's prescription for a drug containing excipients that could be harmful to a patient or, at least, are highly controversial.

An interesting practice was demonstrated by the ESNEE project (European Study of Neonatal Exposure to Excipients) that studied the possibility of avoiding neonatal exposure to potentially harmful excipients by product substitution with alternative excipients-ofinterest free formulations available in Europe. It is notable that such an approach led to a $44 \%$ reduction in the number of neonates receiving such potentially harmful excipients as parabens, polysorbate 80, propylene glycol, benzoates, saccharin sodium, and sorbitol [35]. These results confirm that it is reasonable to evaluate the risk of additives contained in a pediatric formulation and consider all possible therapeutic alternatives trying to minimize 
the use of potentially harmful excipients by children, especially those of young age group and those having additional health risks.

According to Good Pharmacy Practice, preventing harm from medicines is one of the components of a pharmacist's mission [36]. A pharmacist should evaluate all prescriptions "considering the therapeutic, social, economic and legal aspects of the prescribed indication(s) before supplying medical products to the patient ... Where possible, generic substitution is recommended" [36]. Thus, if evaluation of therapeutic aspects of a drug including active ingredients and excipients as well as the patient's characteristics results in an unfavorable risk/benefit ratio a pharmacist should minimize the harmful effects of the therapy. One of the reasonable solutions could be initiating safer and more effective substitution where it is possible.

This paper presents a review of excipients of the OTC pediatric phytomucolytic syrups, analysis of their safety issues and proposes an approach to the consideration of the excipients' safety risks for a pharmacist in the process of pharmaceutical care. The results of this analysis will be used for developing a specific decision tool for a pharmacist that can be used for enhancing pharmaceutical care when delivering OTC phytomucolytic syrups for children.

\section{Materials and Methods}

Our idea is to analyze two samples of pediatric phytomucolytic syrups available in the pharmaceutical markets of two different countries to eliminate the dependence of the results on the local regulations. Another reason was to confirm our assumption that the safety issues related to the excipients present in pediatric phytomucolytic syrups are not a local health system problem but might be relevant to other countries. Thus, this study determines the need for special approaches and guidelines development that can minimize health risks and ensure the safety of phytomucolytic syrups use in children. We analyzed pharmaceutical excipients contained in two samples of pediatric phytomucolytic syrups, chosen from the twenty best-selling cough syrups available in the Ukrainian and German pharmaceutical markets respectively. Each sample contained 12 pediatric phytomucolytic syrups. Two syrups in each sample have both Ukrainian and German authorization with the same composition of both active ingredients and excipients. According to the leaflet information, the age indications of the syrups varied; the youngest age indication threshold was 1-year-old children. The recommended duration of treatment indicated in the leaflets information corresponded with the general concept of symptomatic treatment and varied in a range of $7 \pm 3$ days.

The safety aspects of excipients in analyzed medications were reviewed using the data of the most authoritative databases and the evidence present in the relevant literature. The information about the list of excipients was obtained from the official leaflets provided at the website of the Ministry of Health of Ukraine as well as official databases and German medical database center DIMDI [37-39]. The analysis of the listed excipients involved the search for its status in FDA Inactive Ingredients Guide (IIG), FDA Food additives database, EU database on Food Additives, Codex General Standard for Food Additives (FAO/WHO) [40-43]. Additionally, the EuFPI STEP database was used as a useful resource of clinical and non-clinical evidence of excipients safety as well as regulatory status information [44]. The review of EMA and WHO guidelines as well as other literature sources on the safety of excipients in pediatric medicines was performed to elicit the key points to consider for pharmaceutical care when dispensing pediatric phytomucolytic syrups $[3,21,29,32,45]$. The detailed analysis data are available in the Supplementary Materials.

The second stage of the study was a microscopic examination of the most popular products from the group of phytomucolytic syrups with Ukrainian authorization. The sample for microscopic examination was $50 \%$ of the group, meaning 6 from 12 syrups. The microscopic examination was aimed at evaluating the homogeneity and the presence of incidental inclusions of herbal material and other residuals. Microscopic examination of the syrups was performed with unchanged micro preparations made by standard slides and 
coverslips. Before making micro preparations, all syrups were manually shaken. For this purpose, a modular light field microscope of research class B-1000BF (Optika, Italy) with a digital camera Optikam HDMI Pro (Optika, Italy) was used. The elements of the ground herbal material in the microscope's field of view were evaluated in 10 micro preparations for each experimental object using special software Optika IsView v. 3.9.0.602 (Optika, Italy). The magnification was set in the range of 100-400 times depending on the current objectives and conditions of the study.

\section{Results}

\subsection{Review of the Composition of the Active Substances and Excipients}

Most of the analyzed syrups contained traditional herbal extracts. Two syrups (Syrup 11 and Syrup 12) were authorized at both the Ukrainian and German markets and thus are represented in both the analyzed samples. One syrup was a phytoneering product containing thyme and ivy extract BNO 1201 (Syrup 11). Phytoneering is a scientific and production concept, implying the creation of herbal medicines with a constant and controlled biochemical composition of biologically active substances of medicinal plants [39].

All excipients identified in the analyzed syrups generally belong to the following functional categories: sweeteners, preservatives, flavors, solvents, emulsifiers, coloring, stabilizing, buffering, solubilizing and viscosity-increasing agents. Most excipients were preservatives and sweeteners (Table 1 ).

Table 1. Analysis of excipients safety in analyzed samples of pediatric phytomucolytic syrups marketed in Ukraine $(n=10)$, in Germany $(n=10)$, and syrups with equivalent authorization in Ukraine and Germany $(n=2)$.

\begin{tabular}{|c|c|c|c|c|c|c|c|c|c|c|c|}
\hline \multirow{2}{*}{$\begin{array}{l}\text { Excipient } \\
\text { Category }\end{array}$} & \multirow[t]{2}{*}{ Excipient Name } & \multirow{2}{*}{ E Code } & \multicolumn{3}{|c|}{ Frequency } & \multicolumn{3}{|c|}{ Total Frequency } & \multicolumn{3}{|c|}{$\begin{array}{l}\text { Total Frequency of } \\
\text { Potentially Harmful } \\
\text { Excipients }\end{array}$} \\
\hline & & & UKR $^{1}$ & GER $^{2}$ & $\begin{array}{l}\text { UKR/ } \\
\text { GER }\end{array}$ & UKR & GER & $\begin{array}{l}\text { UKR/ } \\
\text { GER }\end{array}$ & UKR & GER & $\begin{array}{l}\text { UKR/ } \\
\text { GER }\end{array}$ \\
\hline \multirow{7}{*}{ Sweeteners } & Maltitol & E 965 & - & 2 & 1 & \multirow{7}{*}{11} & \multirow{7}{*}{13} & \multirow{7}{*}{2} & \multirow{7}{*}{11} & \multirow{7}{*}{11} & \multirow{7}{*}{1} \\
\hline & Honey* & - & 1 & - & - & & & & & & \\
\hline & $\begin{array}{l}\text { Sucrose (involving } \\
\text { inverted sugar syrup, }\end{array}$ & - & 7 & 5 & - & & & & & & \\
\hline & $\begin{array}{l}\text { Sugar syrup, etc.) } \\
\text { Sorbitol * }\end{array}$ & E 420 & 3 & 4 & - & & & & & & \\
\hline & Xylitol * & E 967 & - & - & 1 & & & & & & \\
\hline & Sucralose * & E 955 & - & 1 & - & & & & & & \\
\hline & Sodium saccharin * & E 954 & - & 1 & - & & & & & & \\
\hline \multirow{8}{*}{$\begin{array}{l}\text { Preservatives, } \\
\text { antioxidants }\end{array}$} & Sorbic acid & E 200 & 1 & - & - & \multirow{8}{*}{17} & \multirow{8}{*}{10} & \multirow{8}{*}{5} & \multirow{8}{*}{7} & \multirow{8}{*}{4} & \multirow{8}{*}{2} \\
\hline & Potassium sorbate & E 202 & 3 & 3 & 1 & & & & & & \\
\hline & $\begin{array}{c}\text { Citric acid } \\
\text { monohydrate/anhydrous }\end{array}$ & Е 330 & 4 & 2 & 2 & & & & & & \\
\hline & $\begin{array}{l}\text { mononyarate/ annyarous } \\
\text { Sodium benzoate }\end{array}$ & E 211 & 2 & 1 & - & & & & & & \\
\hline & $\begin{array}{l}\text { Methyl } \\
\text { parahydroxybenzoate * }\end{array}$ & E 218 & 4 & 2 & 1 & & & & & & \\
\hline & $\begin{array}{c}\text { Propyl } \\
\text { parahydroxybenxoate* }\end{array}$ & E 216 & 1 & 2 & 1 & & & & & & \\
\hline & $\begin{array}{l}\text { Sodium methyl } \\
\text { parahydroxybenzoate * }\end{array}$ & Е 219 & 1 & - & - & & & & & & \\
\hline & $\begin{array}{l}\text { Sodium propyl } \\
\text { parahydroxybenxoate * }\end{array}$ & Е 217 & 1 & - & - & & & & & & \\
\hline \multirow[t]{2}{*}{ Flavors } & \multirow{2}{*}{$\begin{array}{c}\text { Natural-based } \\
\text { Flavors with risk } \\
\text { components (PG } \\
\text { ethanol) }\end{array}$} & - & 3 & 3 & 1 & \multirow[t]{2}{*}{5} & \multirow[t]{2}{*}{4} & \multirow[t]{2}{*}{1} & \multirow[t]{2}{*}{2} & \multirow[t]{2}{*}{1} & \multirow[t]{2}{*}{-} \\
\hline & & - & 2 & 1 & - & & & & & & \\
\hline \multirow{2}{*}{$\begin{array}{l}\text { Coloring } \\
\text { agents }\end{array}$} & \multirow{2}{*}{$\begin{array}{c}\text { Natural-based } \\
\text { Synthetic } \\
\text { (Brilliant blue FCF) * }\end{array}$} & - & - & - & 1 & \multirow{2}{*}{1} & - & 1 & 1 & _- & _- \\
\hline & & E 133 & 1 & - & - & & & 1 & 1 & & \\
\hline Viscosity- & Acacia & E 414 & - & - & 1 & & & & & & \\
\hline increasing & Maltodextrin & & - & - & 1 & 2 & 1 & 3 & 2 & 1 & 1 \\
\hline agents & Xanthan gum * & E 415 & 2 & 1 & 1 & & & & & & \\
\hline
\end{tabular}


Table 1. Cont.

\begin{tabular}{|c|c|c|c|c|c|c|c|c|c|c|c|}
\hline \multirow{2}{*}{$\begin{array}{l}\text { Excipient } \\
\text { Category }\end{array}$} & \multirow{2}{*}{ Excipient Name } & \multirow{2}{*}{ E Code } & \multicolumn{3}{|c|}{ Frequency } & \multicolumn{3}{|c|}{ Total Frequency } & \multicolumn{3}{|c|}{$\begin{array}{l}\text { Total Frequency of } \\
\text { Potentially Harmful } \\
\text { Excipients }\end{array}$} \\
\hline & & & $\mathrm{UKR}^{1}$ & GER $^{2}$ & $\begin{array}{l}\text { UKR/ } \\
\text { GER }\end{array}$ & UKR & GER & $\begin{array}{l}\text { UKR/ } \\
\text { GER }\end{array}$ & UKR & GER & $\begin{array}{l}\text { UKR/ } \\
\text { GER }\end{array}$ \\
\hline \multirow{4}{*}{ Solvent } & Ethanol in a safe amount & - & 1 & 4 & 1 & \multirow{4}{*}{3} & \multirow{4}{*}{10} & \multirow{4}{*}{1} & \multirow{4}{*}{3} & \multirow{4}{*}{6} & \multirow{4}{*}{-} \\
\hline & Ethanol in a risk amount * & - & 1 & 2 & - & & & & & & \\
\hline & Glycerin * & E 422 & 2 & 1 & - & & & & & & \\
\hline & Propylene glycol* & E 1520 & - & 3 & - & & & & & & \\
\hline $\begin{array}{c}\text { Solubilizing, } \\
\text { agent }\end{array}$ & Hydroxypropyl betadex & - & - & - & 1 & - & - & 1 & - & - & - \\
\hline $\begin{array}{c}\text { Buffering } \\
\text { agent }\end{array}$ & Sodium citrate & E 331 & 1 & 1 & - & 1 & 1 & - & - & - & - \\
\hline $\begin{array}{l}\text { Stabilizing } \\
\text { agents }\end{array}$ & Hydroxyethylcellulose * & - & - & 2 & - & - & 2 & - & - & 2 & - \\
\hline Emulsifier & $\begin{array}{c}\text { Macrogol glyceryl } \\
\text { hydroxystearate } \\
\text { (Polyoxyl } 40 \\
\text { Hydrogenated Castor Oil) }\end{array}$ & - & - & 2 & - & - & 2 & - & - & - & - \\
\hline
\end{tabular}

* - potentially harmful excipients, ${ }^{1}$ UKR—Ukrainian authorization, ${ }^{2}$ GER—German authorization, ${ }^{3}$ PG—propylene glycol.

Our analysis identified several excipients with safety issues contained by analyzed syrups: natural sweeteners with high cariogenic effect and glycemic index, a sweetener with osmotic activity and laxative effect in high doses, artificial sweeteners, synthetic coloring agents, parabens, glycerin, propylene glycol and others. According to the literature data, synthetic coloring agents, propylene glycol, parabens have been associated with the major negative reactions on the human body initiated by excipients. The most relevant safety concerns for potentially harmful excipients are reviewed below.

\subsubsection{Sweeteners}

Sweeteners are the key component of pediatric medications that significantly contribute to compliance and palatability $[7,8]$. However, the use of sweeteners is related to a range of safety issues. Firstly, sweeteners use is highly restricted in children with specific therapeutic conditions such as diabetes, severe renal insufficiency, and food intolerance $[17,46]$. As for other children, the preference also should be given to sweeteners with a low glycemic index or no glycemic response. The significant safety issue in the case of short-term use is the cariogenic effect of some sugars that commonly remain to be the primary hidden risk of pediatric syrups for parents and dentists as well $[19,47,48]$. Sweeteners with a high glycemic index also provide additional calories when cough syrup is consumed by a child. In the case of short-term use of the drug this may not be significant for a child with a normal body mass index; however, the caloricity of a diet is to be strictly considered for children with excessive weight.

Last but not least is the potential of the laxative effect caused by some non-digestible polyols, which is dose-dependent. In high concentrations, sorbitol and mannitol might lead not only to discomfort but to compromised drug bioavailability. This negative effect varies depending on the pharmaceutical properties of the corresponding active ingredient $[10,49]$. For example, it becomes a critical issue in the case of complex therapy or a therapy with antibiotics or other drugs requiring strict dosing. Currently, the most reports of the laxative effect as an adverse reaction are available for sorbitol [17].

The advantage of syrups containing a high concentration of natural-based sugars is that they do not require additional pharmaceutical preservatives [10]. Non-glycogenic polyhydric alcohol or lower sucrose concentration are more preferable sweeteners for pediatric syrups, however, they require the use of preservatives [10]. 
3.1.2. Parabens: Methyl parahydroxybenxoate (Methyl paraben) and Propyl parahydroxybenxoate (Propylparaben)

The analysis shows that five of ten phytomucolytic syrups with only Ukrainian authorization contained parabens, and two of ten German syrups and one syrup with Ukrainian and German authorization did also. Some studies demonstrated that parabens bind to estrogen receptors making an agonistic effect, which has become a source of numerous concerns and debates on parabens safety [45]. Methylparaben did not influence animals' male and female reproductive organs, however, there are animal data available indicating that propylparaben possesses some estrogenic activity (increased uterus weight, accelerated onset of puberty). Another toxicity study of propylparaben revealed a negative effect on spermatogenesis in male rats (a decrease in the testicular and epididymal quantity of spermatozoids) [45,50]. Some studies have been reported that parabens stimulate the proliferation of breast cancer cells [51]. The potential relation of estrogenic activity of parabens and breast cancer development has been discussed in a range of resources because estrogen is considered to be a substantial factor in a majority of human breast cancer development [51].

According to the animal research data reviewed by EMA Committee for Medicinal Products for Human Use (CHMP), lack of a clear NOAEL and potential impairment of reproductive organs propylparaben could be a concern for human safety [45]. Therefore, based on EFSA's opinion dated July 2004 propylparaben was banned for use as a food additive within the European Union since 2006 (Directive 2006/52/EC). For oral pharmaceutical formulations, methylparaben is allowed in oral formulations up to $0.2 \%$ of the product, and, after re-evaluation in 2015, a conservative NOEL of $100 \mathrm{mg} / \mathrm{kg} /$ day has been determined for propylparaben which corresponds to a possible daily intake of $2 \mathrm{mg} / \mathrm{kg} /$ day of propylparaben in adults and pediatric patients [45]. Propylparaben is also mentioned by the WHO among pediatric medicines excipients that mostly caused problems in children [3].

There is a range of data showing the association between parabens exposure and allergic sensitization [52]. In addition to medications, parabens are widely used as preservatives in cosmetics, personal care products, and food [53]. In one study that involved 455 children, it was proved that exposure to propylparaben is related to aeroallergen sensitization and an increase of Eczema Area and Severity Index (EASI) score [52]. Several studies also confirm that parabens are significantly associated with allergic diseases development $[54,55]$. Considering these data and the fact that paraben-sensitive individuals might be consistently exposed to parabens in everyday life by various products, the use of parabens in pediatric medicines should be avoided. This conclusion is completely consistent with the EMA position regarding parabens as sensitizing agents [56].

\subsubsection{Synthetic Coloring Agents}

One of the analyzed syrups with Ukrainian authorization contained synthetic coloring agent Brilliant Blue FCF. This coloring agent is not approved either by FDA or GSFA. It may cause hypersensitivity and hyperkinetic activity, especially among children. In general, the WHO states that the use of coloring agents in pediatric medicines is generally discouraged, especially for infants and young children [57]. EMA requires that the use of any coloring agent must be justified properly in terms of its allergenic potential and minimal toxicological implications in the target age group [29]. These requirements are based on concerns regarding the safety of synthetic coloring agents that have been increasing for many years [9]. One of the most serious issues is a range of study data presenting clear evidence that synthetic dyes affect the behavior of children including those with food allergies, hyperactivity, Attention-Deficit/Hyperactivity Disorder (ADHD), and even children without any allergic or behavioral disorder [58,59]. 


\subsubsection{Solvents: Propylene Glycol (PG), Glycerin, Ethanol}

Some of the analyzed syrups contained propylene glycol as the solvent of coloring and flavoring agents (two Ukrainians and one German syrup). Three syrups from the group of German authorization contained PG as a solvent. A range of side effects of PG has been reported in the literature. This excipient is extensively metabolized in the liver and large volumes ( $8-40 \mathrm{~g} / \mathrm{kg}$ orally) are associated with adverse effects most commonly on the central nervous system (depression), especially in neonates and children $[10,60,61]$. Seizures have been reported following ingestion of propylene glycol used as a vehicle to administer vitamin D [20]. Some data show the ethanol-like apoptotic neurodegeneration develops in the nervous system of the mouse after one single dose of PG starting at doses $2 \mathrm{~g} / \mathrm{kg}$ [61]. Other adverse reactions reported for high doses of PG include: ototoxicity, respiratory arrest and dyspnoea, multisystem organ dysfunction, cardiovascular effects, seizures, hyperosmolarity, and lactic acidosis, both of which occur most frequently in patients with renal impairment [10]. Adverse effects are more likely to occur following the consumption of large quantities of PG or the administration to neonates, children under 4 years of age, pregnant women, and patients with hepatic or renal failure. Interestingly, that American Contact Dermatitis Society (ACDS) has recognized PG to be the "Allergen of the Year" [62]. PG becomes to be present in an extremely large number of products and dermatologists estimate that propylene glycol allergy ranges from $0.8 \%$ to $3.5 \%$ [62]. The most likely allergic reaction is atopic dermatitis, but it can be systemic if the patients take PG orally [63]. In this case, a rash most likely develops within 3 to $16 \mathrm{~h}$ of ingestion. Patients who have atopic dermatitis may be at the highest risk of this allergy. According to the EMA report, the dose limits for PG which are acceptable for short-term use are $50 \mathrm{mg} / \mathrm{kg}$ for children from 1 month to 5 -years-old, and $500 \mathrm{mg} / \mathrm{kg}$ for children older than 5 years. Additionally, the EMA warns about co-administration of PG with other drugs containing PG or any substrate for alcohol dehydrogenase, such as ethanol because this may induce adverse effects in children less than 5-years-old [63]. Medical monitoring is required for patients with renal or liver diseases because of reported risk of acute tubular necrosis, acute renal failure and liver dysfunction [61].

It is worth pointing out that one of the analyzed pediatric phytomucolytic syrups contains PG as well as ethanol—one from the group of syrups with German marketing authorization which is indicated for use by children from 3 years and one Ukrainian syrup indicated for children from 2 years. Ethanol could be considered safe only if its use in a syrup is properly substantiated and it is contained in the acceptable amount mentioned by specific regulations $[64,65]$. This is not the case for one Ukrainian and two German syrups which are indicated for young children and contain ethanol in potentially harmful concentration.

Oral intake of glycerin has a demulcent and mild laxative effect, in large doses it can initiate headache, thirst, nausea, and hyperglycemia. Adverse effects of glycerin are mainly due to the dehydrating properties of glycerin [10].

\subsection{The Comparative Analysis of Excipients with Safety Concerns Found in Phytomucolytic Syrups with Ukrainian and German Marketing Authorization}

To facilitate the analysis of excipients in pediatric phytomucolytic syrups, we decided to categorize all the excipients under consideration into four categories depending on the extent and severity of their effect on a child's body. The first category (no risk) are excipients that are proved to be safe when using in all categories of patients. In our analysis this category involves maltitol, sorbic acid, potassium sorbate, citric acid monohydrate and anhydrous, sodium citrate, sodium benzoate, natural-based coloring agents and flavors, acacia, maltodextrin, hydroxypropyl betadex, ethanol in an acceptable and safe amount, macrogol glyceryl hydroxystearate.

The second category (high-risk) encompasses excipients of high safety risk which can induce long-term, irreversible, severe negative reactions requiring special treatment or significantly deteriorating the body functions. According to the available evidence 
reviewed above, the risk of such reactions could not be eliminated with regards to the following excipients present in analyzed syrups: parabens, synthetic coloring agents, PG.

The third category (specific risk) includes the excipients that do not have a risk of severe harm to the general pediatric population, but which could lead to significant negative responses in particular patients or large doses, and, thus, have specific contraindications and safety considerations. In our analysis these are natural sugars with a high glycemic index that must be strictly considered when administering the phytomucolytic syrups to children with diabetes; honey and sodium saccharin with risk of allergic reactions; ethanol in the amount that can be harmful to children of young age or with concomitant diseases; glycerin which can overdose in young children or specific categories; sorbitol, and xylitol which could bring on significant negative reactions for children with associated risk factors (e.g., gastrointestinal diseases, concomitant medications).

Finally, the fourth category (low risk) involves the excipients which do not expose children to significant risk but do not have GRAS status or have unclear/few safety data available. In our analysis, this category includes xanthan gum, hydroxyethyl cellulose, sucralose. Using this categorization, we made the comparison of the number of excipients regarding their safety concerns in analyzed syrups available in Ukrainian and German pharmaceutical markets (Figure 1). The level of cumulative risks is represented on a negative scale at the $y$ axis corresponding with the number of excipients with any safety risks. The syrups that have both Ukrainian and German marketing authorization are represented in the center and labeled as Syrups 11 and 12.

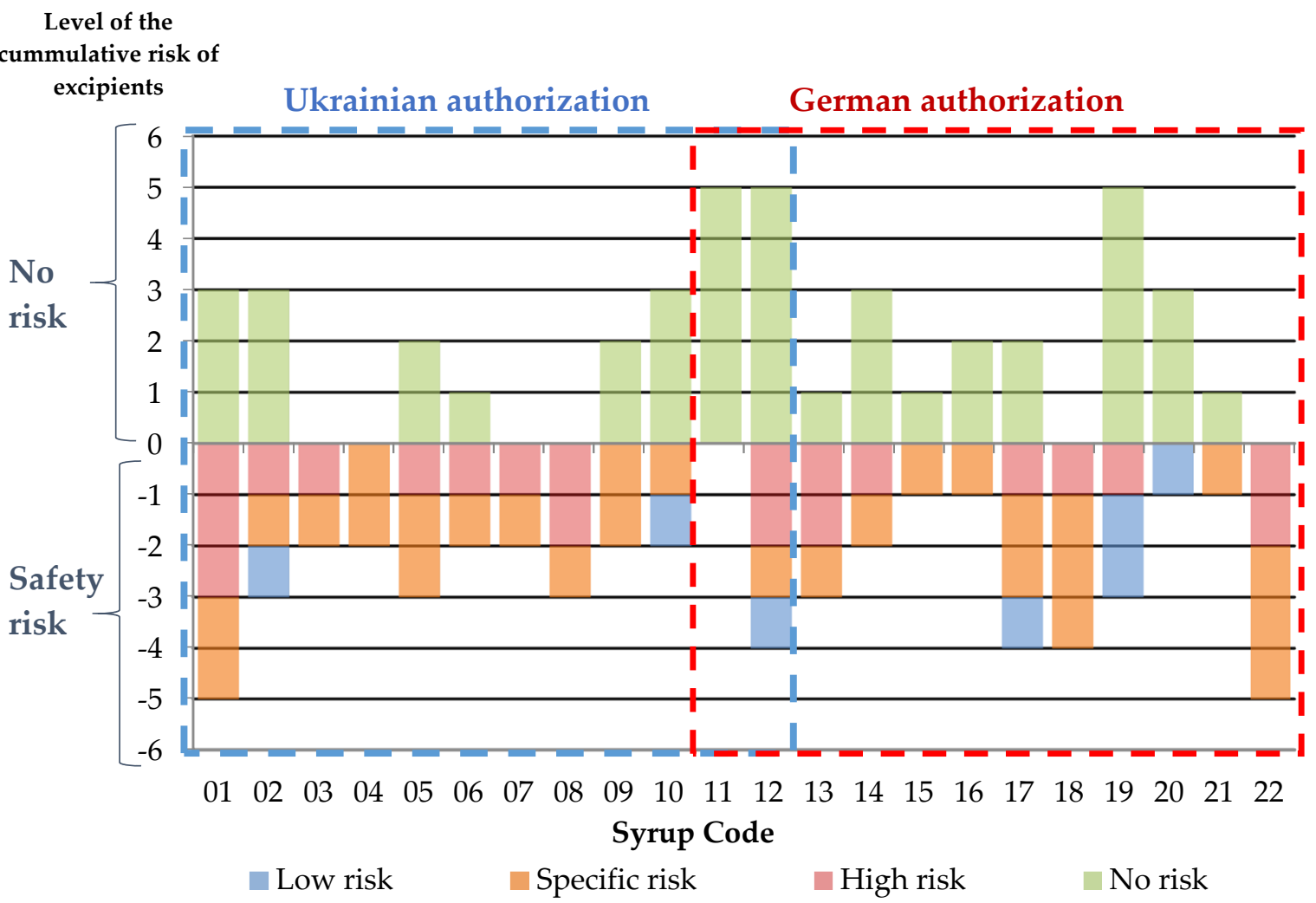

Figure 1. The cumulative safety risk of excipients present in analyzed syrups with Ukrainian and German marketing authorization.

Figure 1 demonstrates the lack of significant differences in the number of the excipients with safety concerns between the two groups of the analyzed syrups (having Ukrainian and German marketing authorization). In each group, almost half of the syrups have at least one excipient of the high-risk category. In addition, in the group of the syrups marketed only in Ukraine one syrup includes two high-risk excipients and one syrup contains three excipients of the high-risk category. In the group of the syrups marketed 
only in Germany, we found two syrups each containing two excipients of the high-risk category. Syrup 12 with both Ukrainian and German authorizations has two high-risk excipients. The excipients assigned to the specific risk category were contained by ten syrups with only Ukrainian marketing authorization and by eight syrups available only in the German market. Syrup 12 contains one specific risk excipient. Finally, the excipients of low risk, assigned to the fourth category, are present in compositions of two syrups with only Ukrainian authorization and three syrups licensed only in Germany. Syrup 11 with both Ukrainian and German authorizations does not contain any risk excipients.

Based on the number of excipients with a safety risk, each of the analyzed groups have one syrup with the maximum cumulative risk (risk level is -5 ). Three syrups licensed only in Ukraine have cumulative risk level -3 , and all others have -1 or -2 risk level. Two syrups licensed only in German have cumulative risk -4 , two syrups have the risk level -3 , and five syrups have -1 or -2 risk levels. It is remarkable that only Syrup 11, which is a phytoneering product, contains 5 excipients that all are safe and do not present any safety risk to all categories of patients to whom this phytoneering syrup can be prescribed.

Based on this comparative analysis we can assume that the issue of safety risks related to the pharmaceutical excipients contained by pediatric phytomucolytic syrups is relevant for many countries regardless of differences in regulation, the coverage, and severity of regulative documents. Therefore, the development of approaches and guidelines for considering the risks of excipients that are present in pediatric phytomucolytic syrups are highly significant for assuring the safety of the treatment and quality pharmaceutical care.

\subsection{Microscopic Examination of Cough Syrups}

The modern concept of pharmaceutical excipients has significantly extended their biological role beyond merely assuring technological aspects and quality of a medical product as a physicochemical system. To date, pharmaceutical excipients are considered as a medium and a regulator of the biological activity of a pharmaceutical product which also corresponds to biopharmaceutical aspects. One of the key features important for achieving proper bioavailability of the herbal preparation is homogeneity.

To examine the consistency, homogeneity, and presence of any inclusions, particles, or aggregations of the studied syrups a microscopic evaluation has been carried out. The studied sample included Syrups 01, 02, 03, 10, 11, and 12 from the group of products with Ukrainian authorization.

Some herbal medicinal products containing extracts can produce sediments that are appropriately labeled by the producers [66]. In this case, a product should have acceptable re-dispersibility to restore the homogeneity and ensure appropriate biopharmaceutic profile. Thus, all the evaluated cough syrups were manually shaken before the microscopic examination and the sample was made from the liquid obtained after shaking. Such a procedure represents in the best way the homogeneity state of a syrup in the moment of consuming by a child. Nevertheless, it was found that only one product (Syrup 11) had a homogeneous structure with single non-significant sediments which are foreseen by the manufacturer (Figure 2). In contrast, other syrups (Syrups 01, 02, 03, 10, and 12) were not homogeneous and contained inclusions, evaluated by the morphologist as being of organic and non-organic origin as well as the residuals of herbal material. These elements are marked with red ovals and narrows (Figure $2 b-f$ ). The inclusions found do not qualify as suspended particles of herbal product and must have been eliminated in the process of extraction according to the good herbal processing practices [57]. Inclusions found in microscopic samples of Syrups 01, 02, 03, 10, and 12 can be assumed as a result of shortcomings in the technology of extract production. The poor homogeneity also might be the result of inadequate excipients or their combination. 


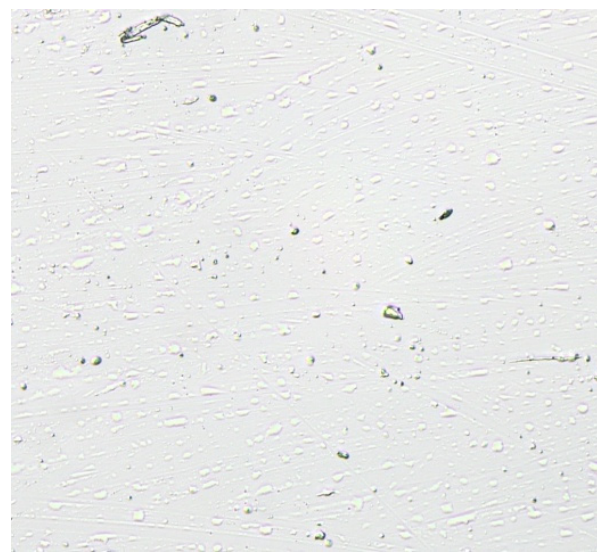

(a)

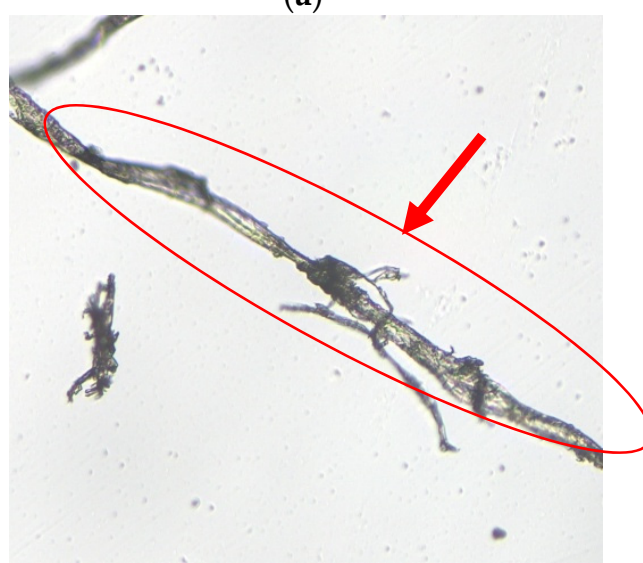

(c)

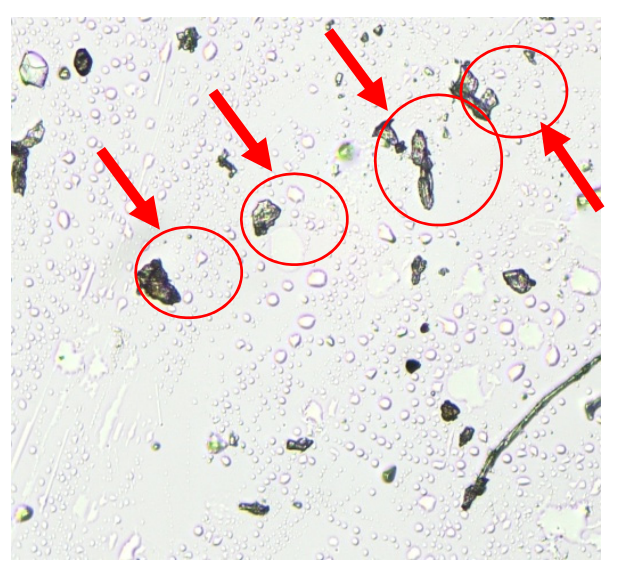

(e)

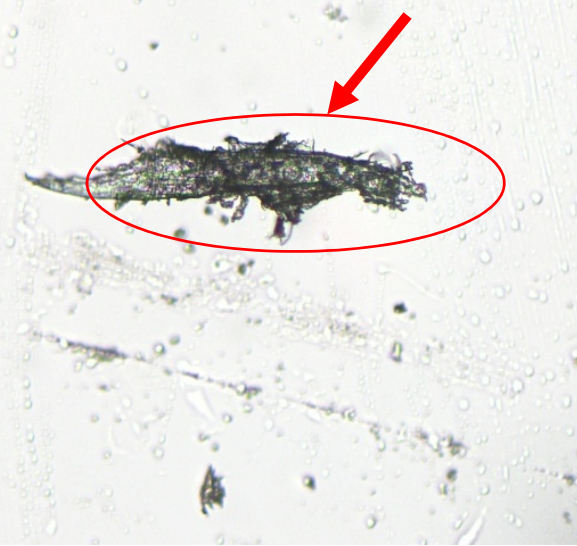

(b)

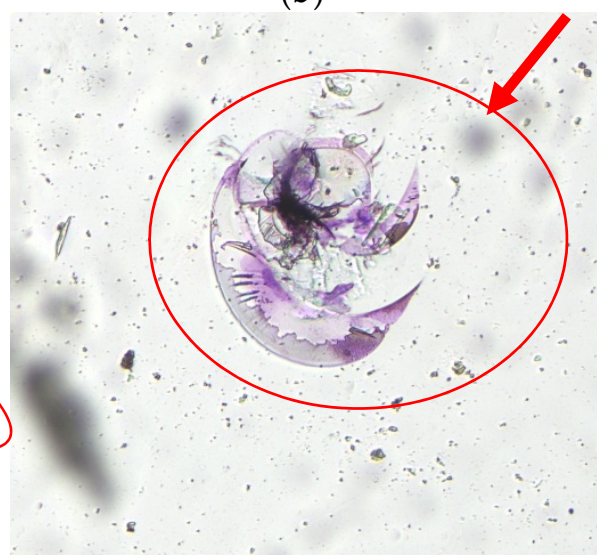

(d)

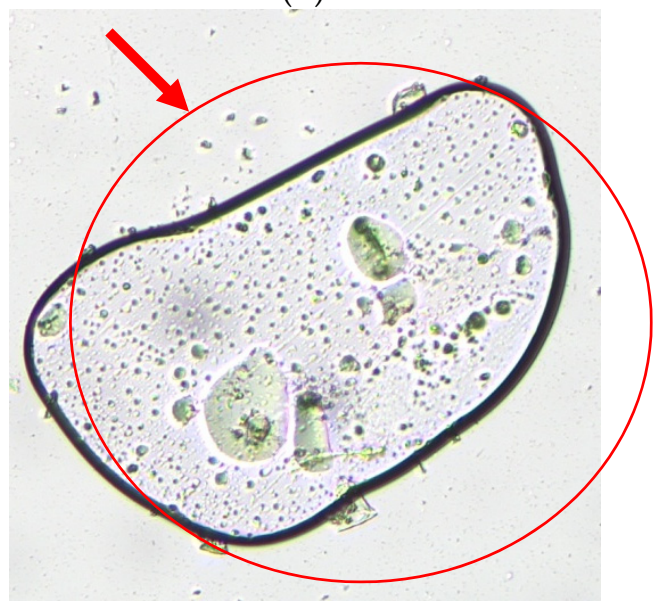

(f)

Figure 2. The microscopic examination of the syrups: (a) Syrup 11; (b) Syrup 01; (c) Syrup 02; (d) Syrup 03; (e) Syrup 10; (f) Syrup 12.

The presence of inclusions might negatively influence the biopharmaceutical features of studied medicines as well as influence their safety and efficacy [57]. It is worth mentioning that the homogeneity of the phytoneering product Syrup 11 is a result of the specific technology used for its production-a low-temperature vacuum extraction in a closed cycle that prevents quantitative and qualitative changes of active components and assures production of the standardized extract [67]. 


\subsection{A "Vicious Circle" of Inadequate Excipient Composition: A Hidden Threat for Clinical Outcomes}

It should be mentioned that besides the negative effect, excipients have a potential for enhancing the medication efficacy. For example, it was shown that the sweet taste of cough syrups is responsible for placebo-effect and cough relief that can even overweigh the pharmacological action of the active components [8]. It is a well-known fact that syrup viscosity also has a very important contribution to the placebo effect $[12,13]$. Viscous syrups can stick to oral mucosa and teeth and prolong sweet taste and flavor sensation making a positive sensory impact in general $[8,68]$. Thus, pharmaceutical producers often use high concentrations of glucose and other sugars, glycerol, and other excipients to increase viscosity and sweetness. However, the attempt to provide the best organoleptic features contributing to the placebo effect, compliance, and product attractiveness, can negatively affect the biopharmaceutics, efficacy, and safety profile of the cough syrup.

For instance, gums (maltodextrin, acacia, xanthan gum) are commonly used for increasing the viscosity of phytomucolytic syrups [10]. However, they are subject to bacterial and enzymatic degradation requiring additional antimicrobial preservatives. Acacia solution may be preserved by methylparaben and propylparaben mixture which have questionable safety profiles, especially when using in children. Maltodextrin solutions may require the addition of an antimicrobial preservative. Moreover, there is a place for unintentional interaction of gums and active ingredients, for example, acacia is incompatible with several substances including thymol which is the main component of many herbal expectorant syrups [10]. In our analysis, such incompatible ingredients were present in Syrup 12 which is available both at the Ukrainian and German markets (Figure 1).

The efficacy of parabens mixture (usually methyl hydroxybenzoate and propyl hydroxybenzoate) can be impaired by the presence of hydrophilic polymers (generally employed to enhance viscosity) because of interaction [10]. To avoid this effect, producers increase the overall preservative concentration which becomes a safety concern again.

Choosing an effective and at the same time a safe preservative is an especially important issue in herbal cough syrups production as they are particularly susceptible to microbial growth. The susceptibility to microbial growth will increase with the presence of different inclusions, e.g., accidental part of plants coming in the process extraction as it has been found in Syrups 01, 02, 03, 10, and 12. Thus, the shortcoming of the extract production procedure will lead to the necessity of using preservatives or other pharmaceutical excipients to enhance the physical and chemical features of the medicine and increasing the shelf-life.

The situation described is considered as a negative consequence of excipients: instead of promoting the effect of active substances, pharmaceutical excipients are added to herbal syrups for amendment of shortcomings in the production of active components-herbal extracts.

An increase in the number and concentrations of excipients used is a risk factor for their negative effects that include allergic and toxic ones, and exacerbation of chronic diseases. Elevated risk of adverse reactions on the one hand and despaired biopharmaceutical profile on the other will result in alteration of clinical response in a child. Lack of efficacy and safety of medicine used might lead to cough intensification, other symptoms aggravation, and overall worsening of a child's state. It is not surprising that a common scenario, in this case, is prescribing additional medicines including another phytomucolytic syrup which might expose a child to the same risks once again. The situation described presents a "vicious circle" where hidden technological and biopharmaceutical issues underlay significant negative clinical outcomes that remain to be inadequately diagnosed (Figure 3). 


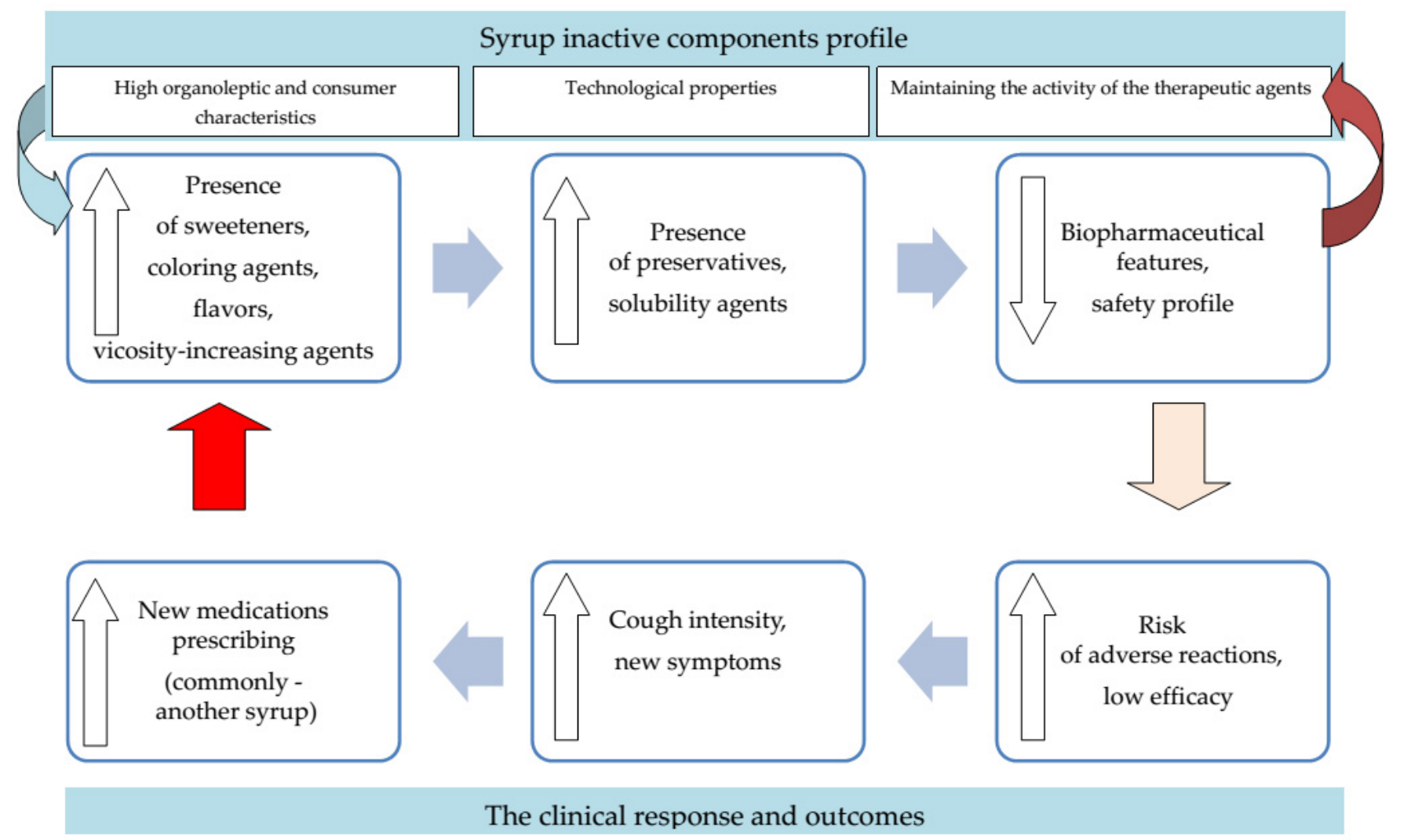

Figure 3. The mechanism of the "vicious circle" initiated by inadequate excipients composition of phytomucolytic syrup.

Children who have more than 6-8 episodes of cold per year are at especially high risk. Considering the fact that the high popularity of cough syrups among parents leads to their uncontrolled use, a lot of children receive cough syrup in each case of a cold, becoming a category of a specially increased risk of sensitization and other negative effects. After years of recurrent respiratory diseases, some of these children develop a chronic condition - bronchial asthma, chronic rhinosinusitis. It would be unfair to ignore the potential contribution of pharmaceutical excipients to the development and progressions of such conditions. To date, there is lack of data concerning this potential contribution, which is an important subject for further research.

The issue described might be common for many phytomucolytic syrups because generally, most herbal medicines lack standardization, stability assurance and quality control, as well as the possible interaction with a pharmaceutical excipient might be unknown [57]. However, this problem can be avoided by strict standardization of extracts production and quality control at each stage of manufacturing. According to the literature data, to date, strict applications of such approaches in herbal medicines production was demonstrated by phytoneering products, one of which is presented in the studied sample of syrups as a Syrup 11 [67].

Thus, the implementation of more stringent requirements for herbal medicines authorization (strengthening the analysis of composition and its substantiation, requirements for high production standardization and quality control) could contribute to mitigating safety risks posed by some phytomucolytic syrups excipients. Well-designed phytomucolytic products in which both active ingredients and excipients are properly substantiated, synergetic, and compatible demonstrate the best practice with regards to safety and efficacy assurance. In this case, it becomes possible to avoid excessive excipients and to assure high efficacy and safety while achieving optimal organoleptic and user advantages. It is worth mentioning that only one of analyzed syrups has no potentially harmful excipients. 
The excipients of Syrup 11 (an international proprietary name BNO 1201), which has both Ukrainian and German authorizations, were as follows: potassium sorbate, maltitol, citric acid monohydrate, hydroxypropyl betadex, ethanol in a safe amount.

For example, maltitol, present in Syrup 11, is a non-cariogenic sweetener with a low calorific value that at the same time provides necessary viscosity and prevents syrup crystallization $[10,19]$. Maltitol is very close to sucrose by relative sweetness and is the most widely used sugar alcohol both in pharmaceutical and food production [47]. Maltitol can be considered as one of the safest, nonallergenic sweeteners because of its natural origin and absence of cariogenic activity. Additionally, maltitol has a low glycemic index and can, therefore, under medical supervision, be included in diets of diabetic patients. As it is not metabolized by oral bacteria, maltitol has an advantage over sorbitol as it does not cause decay of teeth $[7,47,48]$. Maltitol does not crystallize, easily providing better solubility of the syrup and preventing such negative usage events as sticking at the bottle's top ("cap locking") $[8,10]$. Thymol as an active element of the Syrup 11 extract serves also as a preservative making the Syrup 11 "self-preservative" that prevents the necessity to use more preservatives with questionable safety status [69]. Potassium sorbate is generally recognized as safe according to FDA and has no adverse events reported for its oral administration [10]. The reviewed literature does not present evidence for risks of potassium sorbate toxicity or allergic reactions resulted from the intake of phytomucolytic syrups even in the case of overdosing. According to the EFSA Panel opinion, updated in 2015, the ADI of potassium sorbate was changed from $3 \mathrm{mg} / \mathrm{kg}$ bw per day to $11 \mathrm{mg} / \mathrm{kg}$ bw per day, which also allows concluding that potassium sorbate does not present a risk of high toxicity [70]. Citric acid is a nontoxic natural antioxidant that is commonly consumed as a part of a normal diet. It is important to note that ethanol used as a solvent is contained in an acceptable amount in compliance with all international guidelines [64,71]. The safety of hydroxypropyl betadex has been shown in numerous animal toxicity studies, and it is now approved for use in food products and orally administered pharmaceuticals in many countries [10]. The clinical data also demonstrate very good tolerability of Syrup 11 in real-world practice that confirms the safety of the excipients contained in this medicine [72]. What is more, the proven efficacy evidence of phytoneering products allows avoiding long-term treatment and, thus, overuse of a phytomucolytic syrup.

\section{Discussion}

Considering all of the above mentioned, pharmacists can significantly prevent the risk and possible harm of phytomucolytic cough syrups by considering several important aspects in the process of dispensing OTC pediatric cough syrup:

- Check the presence of sweeteners with glycemic potential in children with diabetes or sweeteners that are individually non-tolerated;

- Opt for natural sweeteners rather than artificial ones;

- Check for the presence of non-digestible sweeteners in high concentration (for example, sorbitol) especially for children with gastrointestinal disorders;

- Minimize the use of medicines with cariogenic sweeteners, inform the parents about measures to decrease the cariogenic effect;

- Avoid the use of synthetic coloring agents especially for allergic children;

- Avoid the use of medicines containing potentially harmful excipients with questionable safety profile-these include parabens, PG;

- Check individual contraindications to some excipients.

Syrups containing any of the excipients that could be dangerous for a child in each particular case should be avoided and substituted by a pharmacist according to principles of pharmaceutical care.

The aspects revealed in our study lay the foundation for target safety features of pediatric phytomucolytic syrup. Additionally, some cough syrup might contain some ingredients requiring special labeling according to the EMA guidelines (e.g., glycerin, PG, sucrose). It would be reasonable that a pharmacist provides essential information to 
parents about these ingredients [32]. The decision tool for a pharmacist that encompasses the aspects mentioned above is presented in Figure 4.

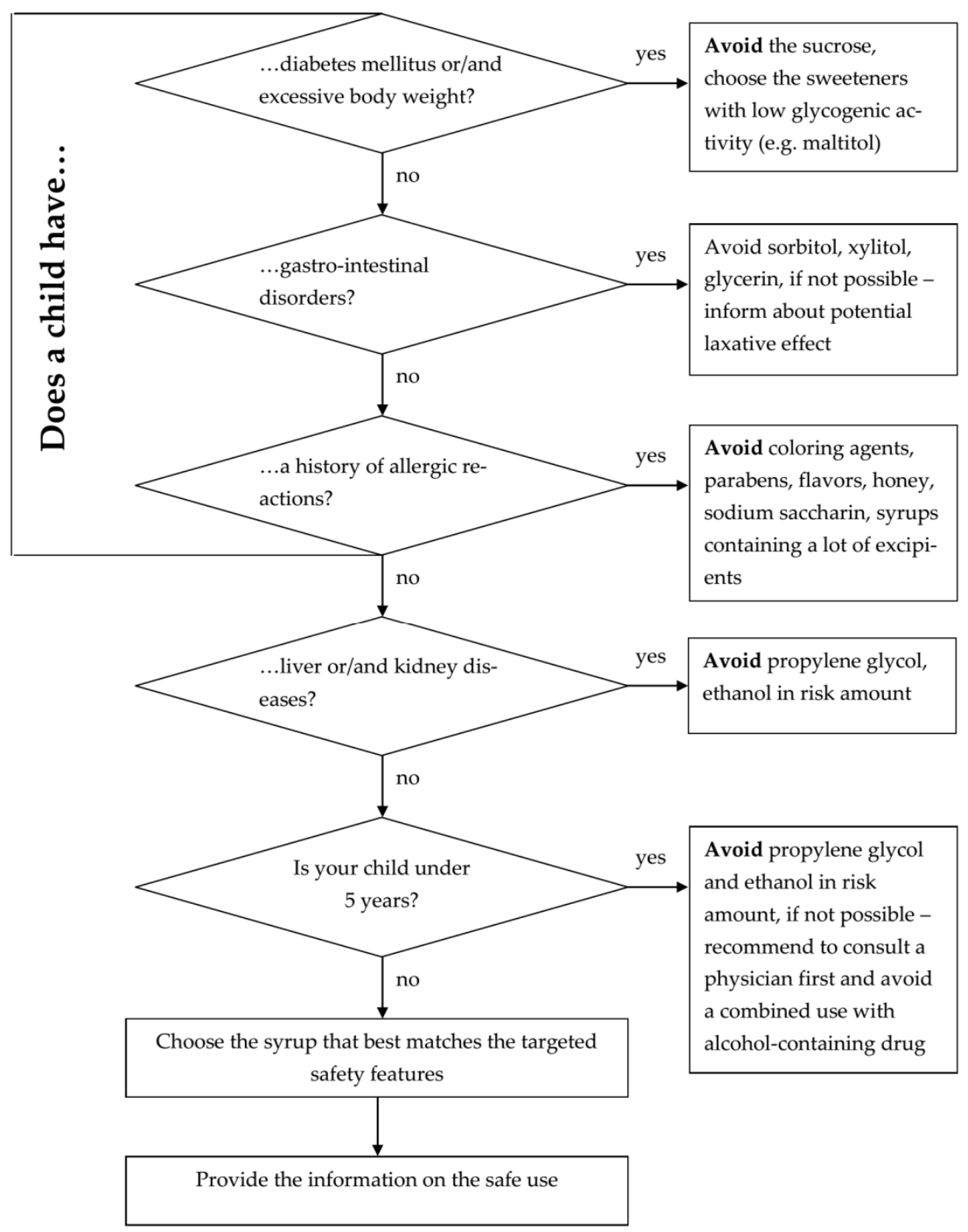

Figure 4. A pharmacist decision-tool for dispense of pediatric phytomucolytic sough syrup.

\section{Conclusions}

The safety of pharmaceutical excipients used in OTC pediatric cough syrups remains to be a controversial issue requiring specific attention. The analysis of the most popular 22 phytomucolytic cough syrups for children in the Ukrainian and German pharmaceutical market has shown that only one-Syrup 11 with BNO 1201 as an active agent-does not contain any potentially harmful excipients. From the 22 analyzed syrups, seven syrups with only Ukrainian authorization, six syrups with German and one syrup with both Ukrainian and German authorizations contain at least one excipient of the high-risk category associated with severe side effects in children and other adverse events (parabens, synthetic coloring agents, PG). These excipients should be avoided as they can induce longterm, irreversible, severe negative reactions requiring special treatment or significantly deteriorating the body functions. 
The excipients of specific risk (ethanol in risk amount, sucrose, honey, and sodium saccharin, glycerin, sorbitol, xylitol) were present in a composition of ten syrups with only Ukrainian marketing authorization, eight syrups with only German marketing authorization and one syrup available in both countries. These agents present a special hidden threat for children with concomitant diseases and predisposition (allergic disorders, diabetes, liver, and kidney dysfunction, etc.). Two Ukrainian syrups, three German and one syrup available in the both countries contain at least one low-risk excipients. Syrup 12 with both Ukrainian and German authorizations has two high-risk excipients. And only one-Syrup 11 which is a phytoneering product with both Ukrainian and German authorizations-does not contain any potentially harmful excipients.

Potentially harmful excipients and inadequate composition of both active ingredients and excipients in a pediatric cough syrup create a "vicious" circle where technological shortcomings result in poor biopharmaceutical and safety profiles, which, in turn, provokes a low efficacy of treatment and a higher risk of adverse reactions. The latter will manifest as increased cough intensity and the appearance of new symptoms in a child. In clinical practice, such outcomes commonly initiate new medical prescriptions with other cough syrups, commonly containing the same controversial excipients. The risks described could be effectively minimized by precautionary measures applied by a pharmacist at the stage of phytomucolytic syrup dispensing.

The paper also presents a pharmacist decision tool that addresses the most relevant risk factors of excipients, considering individual pediatric patients' characteristics. This tool may be implemented in routine pharmacy practice without an excessive burden and can optimize the choice of OTC phytomucolytic syrup for treating cough in children, avoiding possible negative outcomes of the therapy and promoting the best therapeutic results.

We expect that the issue reviewed in this paper will be mirrored in pediatric formulations of other pharmaceutical groups (non-phytomucolytic cough syrups, anti-fever syrups, etc.), thus making ground for further research within this framework.

Supplementary Materials: The following are available online at https:/ /www.mdpi.com/article/10 .3390/scipharm89030032/s1.

Author Contributions: Conceptualization, K.O.Z.; methodology, K.O.Z., O.V.K. and S.K.S.; software, S.K.S.; validation, K.O.Z. and S.K.S.; formal analysis, K.O.Z. and K.L.R.; investigation, K.O.Z. and S.K.S.; resources, S.K.S.; writing—original draft preparation, K.O.Z. and K.L.R.; writing-review and editing, K.O.Z. and O.V.K.; visualization, S.K.S.; supervision, K.O.Z.; project administration, K.O.Z. All authors have read and agreed to the published version of the manuscript.

Funding: This research received no external funding.

Institutional Review Board Statement: Not applicable.

Informed Consent Statement: Not applicable.

Data Availability Statement: The data presented in this study are available in the supplementary material.

Acknowledgments: The authors are grateful to the staff of the Department of Clinical Pharmacology and Clinical Pharmacy of NPhU (Kharkiv, Ukraine), Clinical Diagnostics Laboratory (Kharkiv, Ukraine) and the Head of the Department of Clinical Pharmacology and Clinical Pharmacy, Igor A. Zupanets for providing the material and technical base for the study.

Conflicts of Interest: The authors declare no conflict of interest.

\section{References}

1. Allied Market Research. Available online: https://www.alliedmarketresearch.com/cough-syrup-market-A10312 (accessed on 10 April 2021).

2. Proxima Research. Retail Sale Out Consumption. Available online: http://proximaresearch.ua (accessed on 10 April 2021).

3. World Health Organization. WHO Expert Committee on Specifications for Pharmaceutical Preparations; World Health Organization Technical Report Series No. 961; World Health Organization: Geneva, Switzerland, 2011.

4. Goldsobel, A.B.; Chipps, B.E. Cough in the pediatric population. J. Pediatr. 2010, 156. [CrossRef] 
5. Chang, A.B. Pediatric cough: Children are not miniature adults. Lung 2010, 188. [CrossRef]

6. Klass, P. For a Child's Cough, the Best Medicine Is No Medicine. Available online: https://www.nytimes.com/2018/11/05/well/ family / for-a-childs-cough-the-best-medicine-is-no-medicine.html (accessed on 10 April 2021).

7. Al Humaid, J. Sweetener content and cariogenic potential of pediatric oral medications: A literature. Int. J. Health Sci. 2018, 12, 75-82.

8. Eccles, R. What is the role of over 100 excipients in over the counter (OTC) cough medicines? Lung 2020, 198, 727-734. [CrossRef]

9. Pérez-Ibarbia, L.; Majdanski, T.; Schubert, S.; Windhab, N.; Schubert, U.S. Safety and regulatory review of dyes commonly used as excipients in pharmaceutical and nutraceutical applications. Eur. J. Pharm. Sci. 2016, 93, 264-273. [CrossRef]

10. Rowe, R.C.; Sheskey, P.J.; Quinn, M.E. Handbook of Pharmaceutical Excipients, 6th ed.; Pharmaceutical Press: London, UK; Chicago, IL, USA, 2009.

11. Reker, D.; Blum, S.M.; Steiger, C.; Anger, K.E.; Sommer, J.M.; Fanikos, J.; Traverso, G. Inactive ingredients in oral medications. Sci. Transl. Med. 2019, 11. [CrossRef]

12. Eccles, R. Mechanisms of the placebo effect of sweet cough syrups. Respir. Physiol. Neurobiol. 2006, 152, 340-348. [CrossRef]

13. Eccles, R. The powerful placebo effect in cough: Relevance to treatment and clinical trials. Lung 2020, 198, 13-21. [CrossRef] [PubMed]

14. Earle, C.S. Biopharmaceutics. In Capstone Pharmacy Review; Mason, B.J., Parker, D., Lott, R.S., Eds.; Jones and Bartlett Learning: Burlington, MA, USA, 2014; Chapter 2; pp. 19-29.

15. Batchelor, H.K.; Fotaki, N.; Klein, S. Paediatric oral biopharmaceutics: Key considerations and current challenges. Adv. Drug Deliv. Rev. 2014, 102-126. [CrossRef] [PubMed]

16. Rouaz, K.; Chiclana-Rodríguez, B.; Nardi-Ricart, A.; Suñé-Pou, M.; Mercadé-Frutos, D.; Suñé-Negre, J.M.; Pérez-Lozano, P.; García-Montoya, E. Excipients in the paediatric population: A review. Pharmaceutics 2021, 13, 387. [CrossRef] [PubMed]

17. Dash, R.P.; Srinivas, N.R.; Babu, R.J. Use of sorbitol as pharmaceutical excipient in the present day formulations-issues and challenges for drug absorption and bioavailability. Drug Dev. Ind. Pharm. 2019, 45, 1421-1429. [CrossRef] [PubMed]

18. Yochana, S.; Yu, M.; Alvi, M.; Varenya, S.; Chatterjee, P. Pharmaceutical excipients and pediatric formulations. Chim. Oggi Chem. Today 2012, 30, 56-61.

19. Ruiz-Ojeda, F.J.; Plaza-Díaz, J.; Sáez-Lara, M.J.; Gil, A. Effects of sweeteners on the gut microbiota: A review of experimental studies and clinical trials. Adv. Nutr. 2019, 10, S31-S48. [CrossRef]

20. Lim, T.Y.; Poole, R.L.; Pageler, N.M. Propylene glycol toxicity in children. J. Pediatr. Pharmacol. Ther. 2014, 19, 277-282. [CrossRef]

21. Mcglue, K. European Regulations for Excipients and the Application of EXCiPACT; EXCiPACT: Mumbai, India, 2018.

22. Osterberg, R.E.; See, N.A. Toxicity of excipients-A Food and Drug Administration perspective. Int. J. Toxicol. 2003, 22, 377-380. [CrossRef] [PubMed]

23. Walsh, J.; Cram, A.; Woertz, K.; Breitkreutz, J.; Winzenburg, G.; Turner, R.; Tuleu, C. Playing hide and seek with poorly tasting paediatric medicines: Do not forget the excipients. Adv. Drug Deliv. Rev. 2014, 73, 14-33. [CrossRef]

24. Biggs, J.; Yoo, A.; Lardieri, A.; Morgan, J. Alcohol Content in Pediatric Liquid Formulations. Presented at the Annual Meeting of the Pediatric Pharmacy Advocacy Group, Salt Lake City, Utah, USA, April, 2018. Available online: http://hdl.handle.net/10713/7776 (accessed on 10 April 2021).

25. Christensen, M.L. Best pharmaceuticals for children act and pediatric research equity act: Time for permanent status. J. Pediatr. Pharmacol. Ther. 2012, 17, 140-141. [CrossRef]

26. Sayid, R. Banned E Numbers Found in Over-the-Counter Medicines for CHILDREN. Available online: https:/ / www.mirror.co. uk/news/uk-news/banned-e-numbers-found-over-the-counter-2478068 (accessed on 10 April 2021).

27. Dart, R.C.; Paul, I.M.; Bond, G.R.; Winston, D.C.; Manoguerra, A.S.; Palmer, R.B.; Kauffman, R.E.; Banner, W.; Green, J.L.; Rumack, B.H. Pediatric fatalities associated with over the counter (nonprescription) cough and cold medications. Ann. Emerg. Med. 2009, 53, 411-417. [CrossRef]

28. Murgia, V.; Manti, S.; Licari, A.; De Filippo, M.; Ciprandi, G.; Marseglia, G.L. Upper respiratory tract infection-associated acute cough and the urge to cough: New insights for clinical practice. Pediatr. Allergy Immunol. Pulmonol. 2020, 3-11. [CrossRef]

29. European Medicines Agency. Guideline on Pharmaceutical Development of Medicines for Paediatric Use; European Medicines Agency: London, UK, 2014; pp. 1-24.

30. Salunke, S.; Liu, F.; Batchelor, H.; Walsh, J.; Turner, R.; Ju, T.R.; Tuleu, C. European paediatric formulation initiative (EuPFI)— Formulating ideas for better medicines for children. AAPS PharmSciTech 2017, 257-262. [CrossRef]

31. Van Riet-Nales, D.A.; Kozarewicz, P.; Aylward, B.; de Vries, R.; Egberts, T.C.G.; Rademaker, C.M.A.; Schobben, A.F.A.M. Paediatric drug development and formulation design-A European perspective. AAPS PharmSciTech 2017, 18, 241-249. [CrossRef]

32. Committee for Human Medicinal Products (CHMP); European Medicines Agency (EMA). Annex to the European Commission Guideline on 'Excipients in the Labelling and Package Leaflet of Medicinal Products for Human Use' (SANTE-2017-11668); Committee for Human Medicinal Products (CHMP); European Medicines Agency (EMA): London, UK, 2019; pp. 1-20.

33. European Parliament and the Council. Guidelines on the Formalised Risk Assessment for Ascertaining the Appropriate Good Manufacturing Practice for Excipients of Medicinal Products for Human Use (2015/C 95/02); European Parliament and the Council: London, UK, 2015; pp. 10-13.

34. Pidpruzhnykov, Y.; Ruban, O.; Kolisnyk, T. A new method for risk assessment of pharmaceutical excipients. Pharm. Technol. 2018, $30,28-33$. 
35. Nellis, G.; Metsvaht, T.; Varendi, H.; Lass, J.; Duncan, J.; Nunn, A.J.; Turner, M.A.; Lutsar, I. Product substitution as a way forward in avoiding potentially harmful excipients in neonates. Pediatr. Drugs 2016, 18, 221-230. [CrossRef]

36. International Pharmaceutical Federation (FIP); World Health Organization (WHO). Joint FIP/WHO Guidelines on Good Pharmacy Practice: Standards for Quality of Pharmacy Services; WHO Technical Report Series, No. 961, 2011; International Pharmaceutical Federation (FIP); World Health Organization (WHO): Hague, The Netherlands, 2011.

37. Legislative and Regulative Documents. Ministry of Health of Ukraine. Available online: https://mozdocs.kiev.ua/ (accessed on 10 April 2021).

38. Compendium-Medicines. Available online: https://compendium.com.ua/uk/ (accessed on 10 April 2021).

39. German Medical Database Center DIMDI. Available online: https://portal.dimdi.de/websearch/servlet/Gate?accessid= freeSelectDe\#__DEFANCHOR__(accessed on 12 April 2020).

40. FDA. Food Additive Status List. Available online: https://www.fda.gov/food/food-additives-petitions/food-additive-statuslist\#ftnM (accessed on 10 April 2021).

41. FDA. Inactive Ingredient Search for Approved Drug Products. Available online: https://www.accessdata.fda.gov/scripts/cder/ iig/index.cfm (accessed on 10 April 2021).

42. EMA. Food Additives Database. Available online: https://webgate.ec.europa.eu/foods_system/main/index.cfm (accessed on 10 April 2021).

43. FAO/WHO Food Standards. Codex Alimentarius. GSFA Online. Available online: http://www.fao.org/gsfaonline/additives/ details.html?id=148 (accessed on 10 April 2021).

44. EuFPI STEP Database. Safety and Toxicity of Excipients for Paediatrics. Available online: https://step-db.ucl.ac.uk/eupfi/ appDirectLink.do?appFlag=login (accessed on 8 June 2021).

45. Committee for Human Medicinal Products (CHMP); European Medicines Agency (EMA). Reflection Paper on the Use of Methyland Propylparaben as Excipients in Human Medicinal Products for Oral Use; Committee for Human Medicinal Products (CHMP); European Medicines Agency (EMA): London, UK, 2015.

46. Corazza, G.R.; Strocchi, A.; Rossi, R.; Sirola, D.; Gasbarrini, G. Sorbitol malabsorption in normal volunteers and in patients with coeliac disease. Gut 1988, 29, 44-48. [CrossRef] [PubMed]

47. Saraiva, A.; Carrascosa, C.; Raheem, D.; Ramos, F.; Raposo, A. Natural sweeteners: The relevance of food naturalness for consumers, food security aspects, sustainability and health impacts. Int. J. Environ. Res. Public Health 2020, 17, 6285. [CrossRef] [PubMed]

48. European Food Safety Authority (EFSA). Call for Technical Data on Sweeteners Authorised as Food Additives in the EU; European Food Safety Authority (EFSA): Parma, Italy, 2019; pp. 1-4.

49. Chen, M.L.; Straughn, A.B.; Sadrieh, N.; Meyer, M.; Faustino, P.J.; Ciavarella, A.B.; Meibohm, B.; Yates, C.R.; Hussain, A.S. A modern view of excipient effects on bioequivalence: Case study of sorbitol. Pharm. Res. 2007, 24, 73-80. [CrossRef] [PubMed]

50. Snodin, D. Regulatory risk assessments: Is there a need to reduce uncertainty and enhance robustness? Update on propylparaben in relation to its EU regulatory status. Hum. Exp. Toxicol. 2017, 36, 1007-1014. [CrossRef]

51. Tade, R.S.; More, M.P.; Chatap, V.K.; Deshmukh, P.K.; Patil, P.O. Safety and toxicity assessment of parabens in pharmaceutical and food products. Invent. Rapid Pharm. Pract. 2018, 2018, 1-9. [CrossRef]

52. Lee, Y.; Lee, E.; Yon, D.K.; Jee, H.M.; Baek, H.S.; Lee, S.W.; Cho, J.Y.; Han, M.Y. The potential pathways underlying the association of propyl-paraben exposure with aeroallergen sensitization and EASI score using metabolomics analysis. Sci. Rep. 2021, 11, 1-10. [CrossRef]

53. Fransway, A.F.; Fransway, P.J.; Belsito, D.V.; Yiannias, J.A. Paraben toxicology. Dermatitis 2019, 30, 32-45. [CrossRef]

54. Savage, J.H.; Matsui, E.C.; Wood, R.A.; Keet, C.A. Urinary levels of triclosan and parabens are associated with aeroallergen and food sensitization. J. Allergy Clin. Immunol. 2012, 130, 1-19. [CrossRef] [PubMed]

55. Lincho, J.; Martins, R.C.; Gomes, J. Paraben compounds-Part I: An overview of their characteristics, detection, and impacts. Appl. Sci. 2021, 11, 2307. [CrossRef]

56. European Medicines Agency. Formulation of Choice for the Paediatric Population; European Medicines Agency: London, UK, 2006; pp. 1-45.

57. World Health Organisation. Annex 1: WHO Guidelines on Good Herbal Processing Practices for Herbal Medicines; WHO Technical Report Series No. 1010; World Health Organization: Geneva, Switzerland, 2018; pp. 81-152.

58. Pane, D.N.; El Fikri, M.; Ritonga, H.M. Seing red. J. Chem. Inf. Model. 2018, 53, 1689-1699.

59. Trasande, L.; Shaffer, R.M.; Sathyanarayana, S. Food additives and child health. Pediatrics 2018, 142, e20181408. [CrossRef]

60. Narang, A.S.; Boddu, S.H. Excipient Applications in Formulation Design and Drug Delivery. In Excipient Applications in Formulation Design and Drug Delivery; Springer: Cham, Switzerland, 2015; pp. 1-681. [CrossRef]

61. European Medicines Agency. Propylene Glycol Used as an Excipient. Report Published in Support of the "Questions and Answers on Propylene Glycol Used as an Excipient in Medicinal Products for Human Use"; European Medicines Agency: London, UK, 2017; pp. 1-10.

62. Wick, J.Y. And the Allergen Winner Is: Propylene Glycol! Available online: https:/ / www.contemporaryclinic.com/view/andthe-allergen-winner-is-propylene-glycol (accessed on 12 April 2021).

63. Committee for Medicinal Products for Human Use (CHMP). Assessment Report Propylene Glycol in Medicinal Products for Children International; Committee for Medicinal Products for Human Use (CHMP), 2014. 
64. European Medicines Agency. Ethanol Content in Herbal Medicinal Products and Traditional Herbal Medicinal Products Used in Children; European Medicines Agency: London, UK, 2010; pp. 1-8.

65. Committee for Human Medicinal Products (CHMP); European Medicines Agency (EMA). Questions and Answers on Ethanol in the Context of the Revision of the Guideline "Excipients in the Label and Package Leaflet of Medicinal Products for Human Use"; Committee for Human Medicinal Products (CHMP); European Medicines Agency (EMA): London, UK, 2013; pp. 1-14.

66. Committee for Human Medicinal Products (CHMP); Committee for Human Medicinal Products (CHMP); Committee on Herbal Medicinal Products (HMPC); European Medicines Agency. Guideline on Specification: Test Procedures and Acceptance Criteria for Herbal Substances, Herbal Preparations and Herbal Medicinal Products/Traditional Herbal Medicinal Products; European Medicines Agency: London, UK, 2011; pp. 1-25.

67. Seibel, J.; Pergola, C.; Werz, O.; Kryshen, K.; Wosikowski, K.; Lehner, M.D.; Haunschild, J. Bronchipret ${ }^{\circledR}$ syrup containing thyme and ivy extracts suppresses bronchoalveolar inflammation and goblet cell hyperplasia in experimental bronchoalveolitis. Phytomedicine 2015, 22, 1172-1177. [CrossRef]

68. Wise, P.M.; Breslin, P.A.S.; Dalton, P. Effect of taste sensation on cough reflex sensitivity. Lung 2014, 192, 9-13. [CrossRef]

69. Falcone, P.; Speranza, B.; Del Nobile, M.A.; Corbo, M.R.; Sinigaglia, M. A study on the antimicrobial activity of thymol intended as a natural preservative. J. Food Prot. 2005, 68, 1664-1670. [CrossRef]

70. European Food Safety Authority (EFSA). Scientific opinion on the re-evaluation of sorbic acid (E 200), potassium sorbate (E 202) and calcium sorbate (E 203) as food additives. EFSA J. 2015, 13, 1-91. [CrossRef]

71. FDA. Department of Health and Human Services. 21 CFR Part. 328. Over-the-Counter Drug Products Intended for Oral Ingestion That Contain Alcohol; FDA, Department of Health and Human Services: Rockville, MD, USA, 2010; Volume 75, pp. 56928-56935. [CrossRef]

72. Marzian, O. Behandlung Der Akuten Bronchitis Bei Kindern Und Jugendlichen. Anwendungsbeobachtung Bestätigt Nutzen Und Unbedenklichkeit Einer Flüssigextrakt-Kombination Aus Thymiankraut Und Efeublättern. Fortschr. Med. 2007, 149, 69-74. 